\title{
Trends and correlates of driving under the influence of alcohol among different types of adult substance users in the United States: a national survey study
}

Ji-Yeun Park ${ }^{1 *}$ and Li-Tzy Wu 1,2,3, $^{*}$

\begin{abstract}
Background: Despite a decrease in driving under the influence of alcohol (DUIA) prevalence over the past decades, DUIA prevalence still remains high in the United States. To date, there is limited research examining whether different types of substance users have different trends in DUIA. This study sought to assess trends and variables associated with DUIA by substance use type.

Methods: National Survey on Drug Use and Health (NSDUH) is a cross-sectional, nationally representative population-based survey. By using the NSDUH 2008-2014, we performed the Joinpoint analysis to identify time trends of DUIA in each group of substance users (aged $\geq 18$ years). Logistic regression analysis was used to explore association between substance use type and DUIA and to identify variables associated with DUIA.

Results: Adults who reported alcohol or drug use in the past year were classified into different groups based on past-year substance use status: alcohol use only $(n=141,521)$ and drug use regardless alcohol use. Drug users included prescription opioids only $(n=5337)$, marijuana only $(n=32,206)$, other single drug $(n=3789)$, prescription opioids-marijuana ( $n=3921)$, multiple prescription drugs $(n=1267)$, and other multiple drugs $(n=18,432)$. The Joinpoint analysis showed that DUIA prevalence decreased significantly from 2008 to 2014 among alcohol only users (Average Annual Percent Change $[A A P C]=-2.8$ ), prescription opioids only users (AAPC $=-5.4$ ), marijuana only users (AAPC $=-5.0$ ), prescription opioids-marijuana users (AAPC $=-6.5$ ), multiple prescription drug users (AAPC $=-7.4)$, and other multiple drug users (AAPC $=-3.2$ ). Although the estimate was not statistically significant, other single drug users showed a decreasing trend (AAPC $=-0.9$ ). Substance use type was significantly associated with DUIA in the adjusted logistic regression. All drug use groups, relative to the alcohol only group, had elevated odds of DUIA, and the odds were especially elevated for the multiple drug use groups (prescription opioids-marijuana, adjusted odds ratio $[A O R]=2.71$; multiple prescription drugs, $A O R=2.83$; and other multiple drugs, $A O R=3.68$ ). Additionally, younger age, male sex, being white, higher income, and alcohol abuse/dependence were positively associated with DUIA.
\end{abstract}

Conclusions: DUIA prevalence decreased over time and the magnitude of this reduction differed by substance use type. DUIA interventions need to be tailored to substance use type and individual characteristics.

Keywords: Alcohol-impaired driving, Prevalence, Trends, Drug use type, Marijuana, Opioids, Polydrug use

\footnotetext{
*Correspondence: pjy0225@gmail.com; litzy.wu@duke.edu

'Department of Psychiatry and Behavioral Sciences, BOX 3903, Duke

University School of Medicine, Durham, NC, USA

Full list of author information is available at the end of the article
}

(c) The Author(s). 2019 Open Access This article is distributed under the terms of the Creative Commons Attribution 4.0 International License (http://creativecommons.org/licenses/by/4.0/), which permits unrestricted use, distribution, and reproduction in any medium, provided you give appropriate credit to the original author(s) and the source, provide a link to the Creative Commons license, and indicate if changes were made. The Creative Commons Public Domain Dedication waiver (http://creativecommons.org/publicdomain/zero/1.0/) applies to the data made available in this article, unless otherwise stated. 


\section{Background}

During the past few decades in the United States, the prevalence of driving under the influence of alcohol (DUIA) has decreased [1, 2]. Results from the National Survey on Drug Use and Health (NSDUH) showed that from 2005 to 2014, there was a 37\% proportional decline in DUIA prevalence among US adults aged 18-24 years [3]. According to the 2013-2014 National Roadside Surveys of Alcohol and Drug Use by Drivers, the percentage of weekend nighttime drivers with breath alcohol concentration of .005-.049, .050-.079, and .08+ was 5.2, 1.6, and $1.5 \%$, respectively; these percentages were remarkably lower as compared with 22.3, 6.1, and 7.5\% in 1973 [4]. However, DUIA is still an important public health problem because prevalence rates remain high. According to results from the $2016 \mathrm{NSDUH}, 8.2 \%$ of Americans aged 16 or older reported DUIA during the past year [5]. DUIA can pose a serious safety concern because alcohol is responsible for fatal crashes [6-8]. Alcohol-impaired driving crashes accounted for $28 \%$ of overall fatalities in the United States in 2016 [9]. Data from the US Department of Transportation Fatality Analysis Reporting System also showed that the prevalence of alcohol involvement in fatal crashes from 1999 to 2010 was at approximately 39\% [10]. Economic costs associated with alcohol-involved crashes were estimated to be $\$ 52$ billion [11].

Several studies examined the prevalence trends of DUIA in the United States by subgroup characteristics, such as race/ethnicity, sex, age, and drinking category [2, 12-15]; the prevalence of DUIA was higher among younger people, male, and people who reported binge drinking than their counterparts. However, populationbased data on DUIA trends by substance use type are scarce. DUIA trends among marijuana users and prescription opioid misusers may be of particular interest because simultaneous or concurrent use of alcohol and these two drugs is commonly reported [16-19]. The use of both alcohol and marijuana was reported by $23 \%$ of US high school seniors who participated in the Monitoring the Future (MTF) study [20]. In another study using the MTF data, more than half of high school prescription opioid misusers reported use of prescription opioids and alcohol [21]. In the sample of motor vehicle crashes, marijuana was the most frequently detected non-alcohol substance [22]. The odds of fatal crashes increased significantly with combined use of alcohol and marijuana [23]. There is also evidence that fatal crashes among prescription opioid misusers is a growing concern. Between 1999 and 2000 and 2009-2010, the greatest increase in fatally injured drivers was associated with prescription narcotics; specifically, the prevalence of fatally injured drivers tested positive for hydrocodone/oxycodone increased over six times during the study period [24].
Marijuana and prescription opioids' contribution to fatal crashes suggests a need for more research on DUIA trends by specific type of substance use.

Besides a single substance use, different types of multiple substance use also need to be taken into account when examining how DUIA trends differ by substance use type. The use of multiple substances was associated with greater probability of hazardous drinking that was found to be associated with increased risk of DUIA [25, 26]. A considerable body of evidence also suggests that multiple substance use was more strongly associated with fatal crashes than single substance use [27-29]. Marijuana and prescription opioids are the most commonly used non-alcohol substances in the United States [5]. Considering that marijuana use is associated with increased risk of prescription opioid misuse [30, 31], it is not surprising that a sizable proportion of prescription opioid misusers reported marijuana use [21, 32]. Despite the existing evidence that marijuana and prescription opioids are the most commonly detected non-alcohol substances in fatally injured drivers [33], DUIA trends among prescription opioids-marijuana users has been understudied. More attention also needs to be paid to the use of multiple prescription drugs as prescription drug misuse is widely considered a major public health issue. In a study of 3038 blood samples of suspected impaired drivers in Netherlands, 33\% were positive for prescription drugs; of whom, $37 \%$ were multiple prescription drug users [34]. In addition, the use of multiple prescription drugs was found to be associated with increased crash risk [35].

Given the lack of research, more information on DUIA trends by single and multiple substance use would be useful in designing and implementing effective interventions to reduce DUIA. Accordingly, this study sought to examine trends and correlates of DUIA in the United States across different types of adult substance users.

\section{Methods \\ Data}

Data came from the 2008-2014 NSDUH public-use data files. The NSDUH is an annual cross-sectional survey supported by the Substance Abuse and Mental Health Services Administration. The NSDUH provides in-depth information on prevalence and patterns of substance use and substance use disorder in the civilian non-institutionalized population aged $\geq 12$ years in the United States. The target population of NSDUH includes residents of households, non-institutional group quarters (e.g., shelters, rooming houses, dormitories), and civilian living on a military base. Individuals living in institutional group quarters (e.g., jails and hospitals), active duty military personnel, and individuals with no fixed address (e.g., homeless) were not included in the NSDUH. In the NSDUH, data were collected 
using computer-assisted interviewing methods. To ensure accuracy, data regarding private and confidential questions (e.g., illicit drug use, mental health, and other sensitive behaviors) were collected using audio computer-assisted self-interviewing [36]. For less sensitive demographic items, computer-assisted personal interviewing was used. The NSDUH employed a multistage area probability sample in each of the 50 states and the District of Columbia. Weighted screening and response rates for the 2008-2014 NSDUH were 81.9-88.8\% and 71.2-74.7\%, respectively.

In this study, we focused on adults (aged $\geq 18$ years) who reported alcohol or drug use in the past year. Adult substance users include "alcohol only users (non-drug use)" and "one or more drug users regardless of alcohol use status." The latter group was further classified into six groups: prescription opioids only; marijuana only; other single drug; prescription opioids-marijuana; multiple prescription drugs; and other multiple drugs. A total of 206,473 adult substance users (aged $\geq 18$ years) from the 2008-2014 NSDUH were analyzed.

\section{Study variables}

Drug use in the past year

NSDUH included information on alcohol and drug use from nine drug categories: marijuana, cocaine, heroin, hallucinogens, inhalants, as well as misuse of prescription pain relievers, tranquilizers, stimulants, and sedatives. In the NSDUH, misuse of prescription drugs was defined as use of medication without a prescription or use only for the experience or feeling caused by medication. Respondents who reported lifetime use of each drug (marijuana, cocaine, heroin, hallucinogens, inhalants, prescription pain relievers, tranquilizers, stimulants, and sedatives) were asked about recency of use. Individuals were considered as past-year substance user if they used alcohol or drug within the past 12 months.

\section{Driving under the influence of alcohol in the past year}

The NSDUH asked respondents, (a) "During the past 12 months, have you driven a vehicle while you were under the influence of a combination of alcohol and illegal drugs used together?" and (b) "During the past 12 months, have you driven a vehicle while you were under the influence of alcohol only?" In the NSUDH, DUIA was defined as positive response to either of the questions (a) or (b).

\section{Alcohol abuse and dependence in the past year}

Alcohol abuse and alcohol dependence were included in the analysis as covariates given a possible association with DUIA [37, 38]. The NSDUH used DSM-IV criteria for substance abuse and dependence [39]. Based on the DSM-IV criteria, those who reported at least one of four alcohol abuse symptoms but did not meet the criteria for alcohol dependence during the past year were considered as having alcohol abuse. Those who reported at least three out of seven alcohol dependence symptoms during the past year were considered as having alcohol dependence.

\section{Sociodemographic characteristics}

Sociodemographic characteristics included age (18-25, 26-34, 35-49, 50+), sex (male and female), race/ethnicity (non-Hispanic White, non-Hispanic Black, Hispanic, Asian/Native Hawaiian/Other Pacific Islander, and other), annual household income $(\leq \$ 49,999, \$ 50,000-\$ 74,999$, and $\geq \$ 75,000$ ), and population density (large metro, small metro, and non-metro). These sociodemographic characteristics were included as covariates in the analysis based on prior findings that indicated a possible association with DUIA [40-43]. Survey year was included as a categorical variable in the descriptive statistics to produce the prevalence of DUIA by year. In the adjusted analysis, survey year was considered as a continuous variable to explore time trends of DUIA.

\section{Statistical analysis}

First, we conducted a descriptive analysis to examine distributions of sociodemographic characteristics across seven different types of adult substance users. We then examined past-year prevalence of DUIA by substance use type. To identify statistically significant changes in DUIA trend over time in each group, the Joinpoint analysis was performed [44]. The Joinpoint analysis was used to identify time points where a statistically significant change in linear slope of the trend occurred. The analysis started with zero joinpoints (a straight line) and assessed model fit by adding up to a maximum number of joinpoints. In the final model, the best-fitting joinpoints were selected [45]. Joinpoint analysis also estimated annual percentage change (APC) and average annual percent change (AAPC) [45]. Finally, logistic regression analysis was performed to explore association between DUIA and substance use type (reference group = alcohol only), adjusting for age, race/ethnicity, sex, annual household income, population density, past-year alcohol abuse/dependence, and survey year. Variables associated with DUIA were also examined using adjusted logistic regression. We reported 95\% confidence intervals (CIs) and adjusted odds ratios (ORs) to help interpretation. All results, except for sample size, were weighted to account for the NSDUH's complex survey designs, such as weighting and clustering effects. All statistical analyses, except the Joinpoint analysis, were performed using SAS 9.4 (Cary, NC). The Joinpoint analysis was performed using the Joinpoint software version 4.7.0.0 (National Cancer Institute, 2019). This study was exempted from the Duke University Health System 
Institutional Review Board due to use of publicly available, de-identification datasets.

\section{Results}

\section{Sociodemographic (Table 1)}

Among all adult substance users $(N=206,473), 78.80 \%$ ( $n=141,521)$ were alcohol only users (non-drug use) and the remaining were drug users regardless of alcohol use status. The proportions of drug use groups were as follows: prescription opioids only $(2.31 \%, n=5337)$, marijuana only $(10.47 \%, n=32,206)$, other single drug $(1.65 \%, n=3789)$, prescription opioids-marijuana $(1.08 \%$, $n=3921)$, multiple prescription drugs $(0.55 \%, n=1267)$, and other multiple drugs $(5.14 \%, n=18,432)$. Past-year alcohol abuse and dependence were much prevalent among multiple drug users (alcohol abuse; $17.36 \%$ and alcohol dependence; 19.71\%) than among alcohol only users (alcohol abuse; 3.57\% and alcohol dependence; $2.93 \%)$.

\section{Prevalence trends of past-year DUIA in the United States, 2008-2014 (Table 2)}

Overall, other multiple drug users had the highest prevalence of past-year DUIA (48.30, 95\% CI: 47.01-49.60), followed by prescription opioids-marijuana users (39.37, 95\% CI: 37.12-41.63), multiple prescription drug users (34.70, 95\% CI: 30.79-38.61), marijuana only users (29.10, 95\% CI: 28.13-30.07), other single drug users (27.50, 95\% CI: 25.43-29.57), and prescription opioids only users (22.16, 95\% CI: 20.20-24.13). Alcohol only users had the lowest prevalence of DUIA $(12.93,95 \% \mathrm{CI}$; 12.65-13.21). Table 2 also displays the results of the joinpoint regression analysis. The final model selected zero joinpoints for all substance use groups, except other single drug users (one joinpoint in 2012) from 2008 to 2014. During the study period, there was significant reduction in DUIA prevalence among alcohol only users $(\mathrm{AAPC}=-2.8,95 \% \mathrm{CI}:-4.7,-0.9)$, prescription opioids only users $(\mathrm{AAPC}=-5.4,95 \% \mathrm{CI}$ : $-9.5,-1.1$ ), marijuana only users $(\mathrm{AAPC}=-5.0,95 \% \mathrm{CI}:-5.8,-4.1)$, prescription opioids-marijuana users (AAPC $=-6.5,95 \%$ CI: $-8.8,-4.0$ ), multiple prescription drug users (AAPC $=-7.4,95 \% \mathrm{CI}:-13.6,-0.8)$, and other multiple drug users $(\mathrm{AAPC}=-3.2,95 \% \mathrm{CI}:-5.0,-1.3)$. The final model selected for DUIA among other single drug users detected one joinpoint in 2012. Although the estimates were not statistically significant, DUIA prevalence among other single drug users increased by $8.7 \%$ per year (APC $=8.7,95 \%$ CI: -13.2 , 36.2) from 2008 to 2012 and then decreased by $17.6 \%$ per year $(\mathrm{APC}=-17.6,95 \%$ CI: -57.2, 58.8) from 2012 to 2014. The AAPC was -0.9 ( $95 \%$ CI: $-12.2,11.9)$ for other single drug users, indicating that from 2008 to 2014, on average, DUIA decreased by $0.9 \%$ per year.
Adjusted logistic regression model predicting variables associated with DUIA (Table 3)

Table 3 displays the results of the adjusted logistic regression analysis. The odds of DUIA varied by substance use type. Compared with alcohol only users, all other substance use groups had increased odds of DUIA. Prescription opioids only users were 1.65 times $(95 \% \mathrm{CI}$ : 1.47-1.86) more likely than alcohol only users to report DUIA. Marijuana only (95\% CI: 2.04-2.32) and other single drug users (95\% CI: 1.88-2.39) had nearly 2 times higher odds of DUIA than alcohol only users, respectively. Using two or more drugs was strongly associated with DUIA. The ORs showed a dose related pattern with multiple drug use groups having greater odds of DUIA than the group either using prescription opioids only or using marijuana only. Compared with alcohol only users, prescription opioids-marijuana and multiple prescription drug users had 2.71 times (95\% CI: 2.43-3.02) and 2.83 times (95\% CI: 2.35-3.41) higher odds of DUIA, respectively. Other multiple drug users had the highest odds of DUIA (adjusted OR $=3.68,95 \%$ CI: 3.40-3.97). Younger age, male sex, being white, higher income, and alcohol abuse/dependence were significant variables associated with DUIA. Survey year was found to be a significant predictor in the adjusted analysis, indicating a decreasing trend of DUIA from 2008 to 2014.

\section{Discussion}

This study examined changes in DUIA trend by substance use type and identified variables associated with DUIA. By using the joinpoint analysis, we estimated the APC and AAPC in each group of substance users over the study period (2008-2014). The largest decline was observed among multiple prescription drug users with the AAPC of $-7.4 \%$. The AAPC was $-6.5 \%$ among prescription opioids-marijuana users, $-5.4 \%$ among prescription opioids only users, $-5.0 \%$ among marijuana only users, $-3.2 \%$ among other multiple drug users, and $-2.8 \%$ among alcohol only users. Single drug users showed the smallest decline (AAPC $=-0.9 \%$ ) from 2008 to 2014, which was not statistically significant. DUIA prevalence among other single drug users increased from 2008 to $2012(\mathrm{APC}=8.7 \%)$ and then decreased from 2012 to 2012 (APC $=-17.6 \%)$. Such decreasing trends of DUIA across all substance use groups, regardless of statistical significance, suggest that national efforts may have reduced DUIA to some extent. However, the estimated prevalence of DUIA among adult substance users still remains considerably high (ranging from 12.93 to $48.30 \%$, overall) and the magnitude of decline in DUIA prevalence differed by substance use type. Clearly, there is a continuing need for prevention efforts to reduce DUIA among all substance use groups at the national level. 


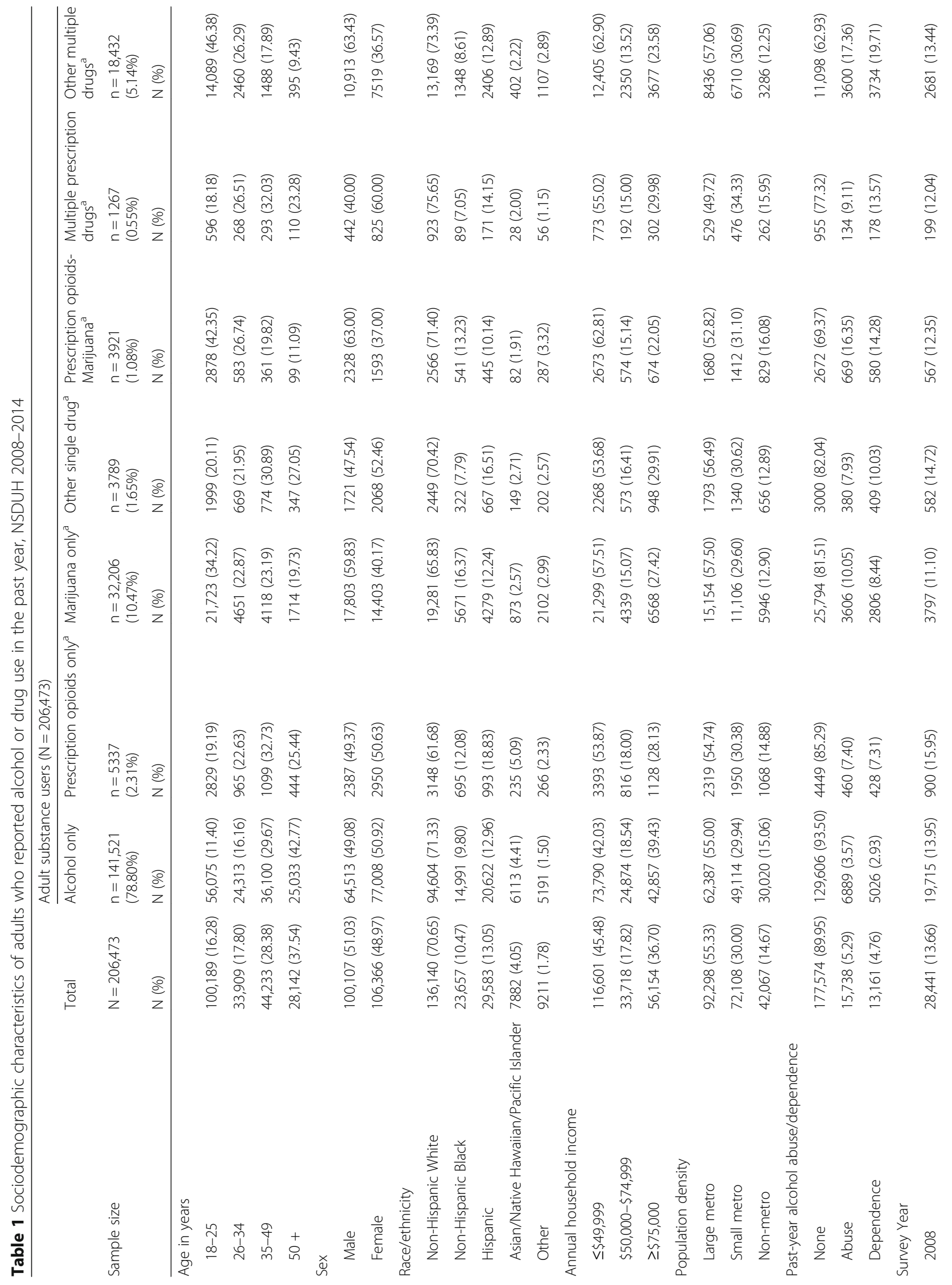




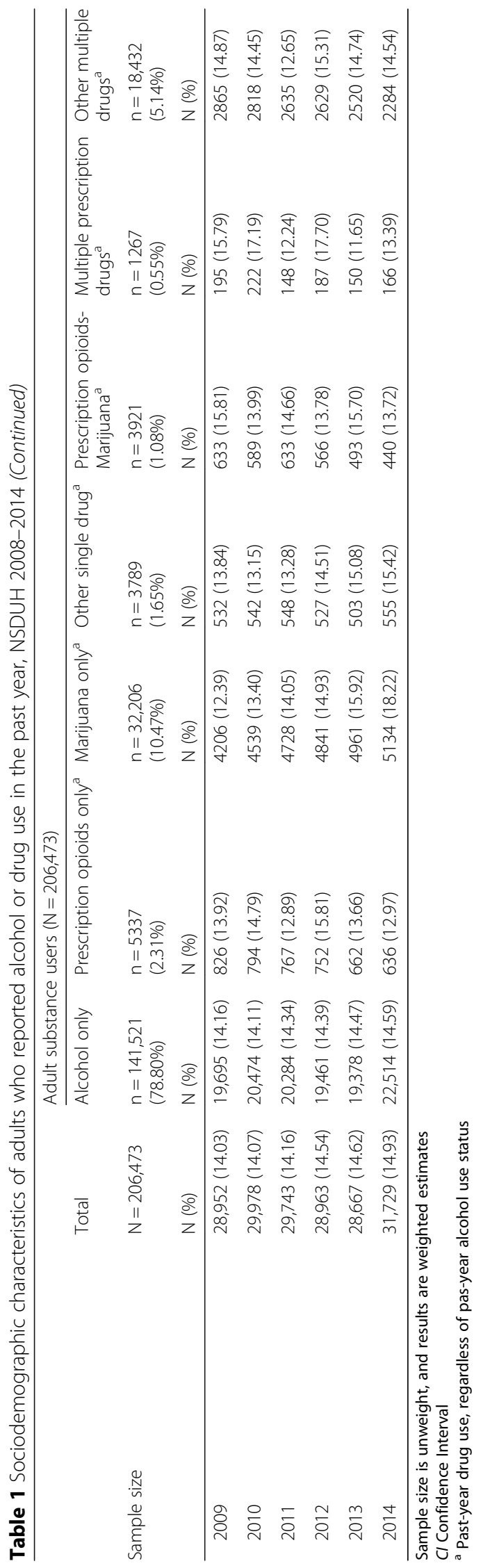




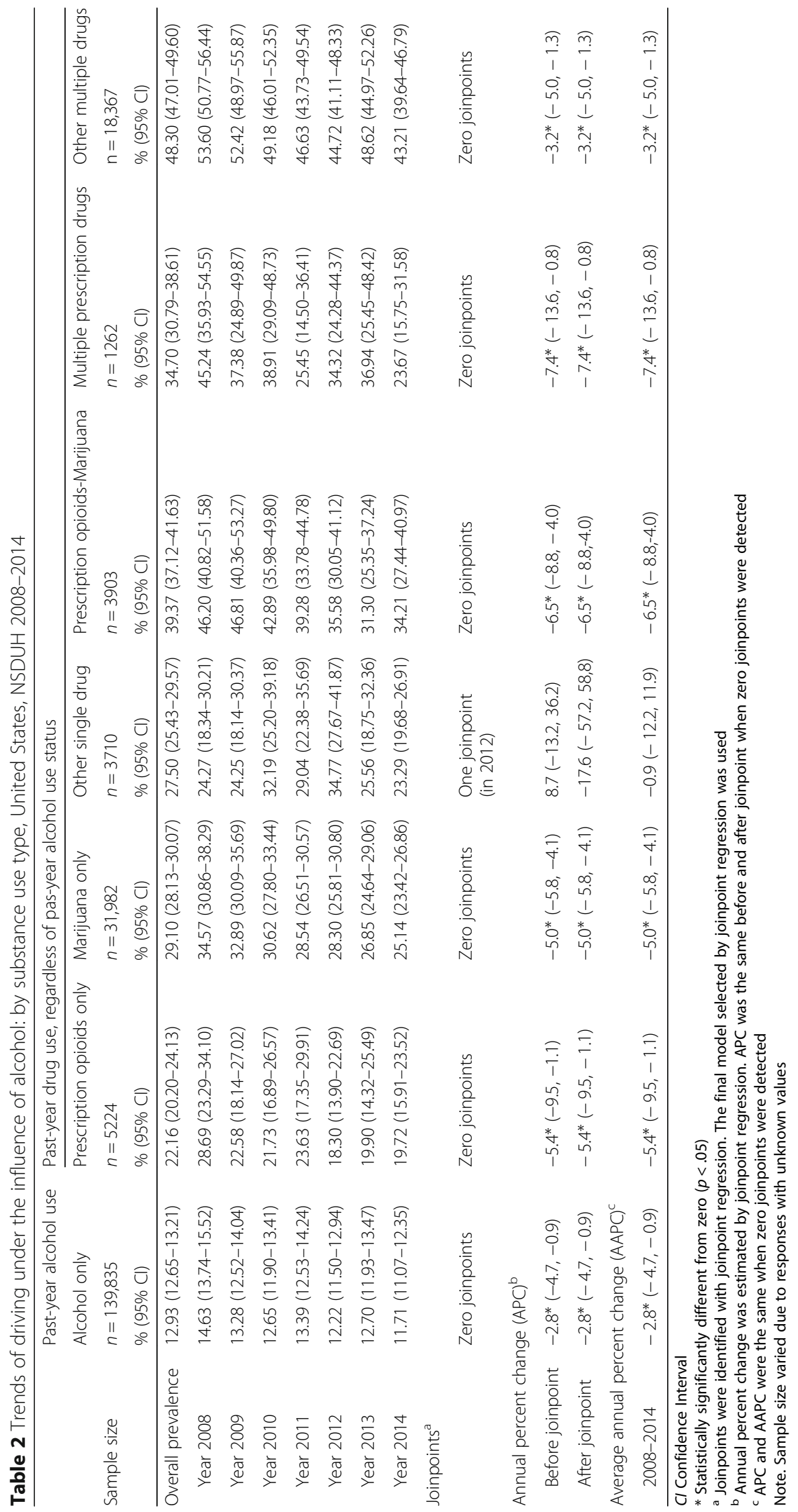


Table 3 Adjusted logistic regression model predicting variables associated with driving under the influence of alcohol

\begin{tabular}{|c|c|}
\hline & $\begin{array}{l}\text { Adjusted OR } \\
(95 \% \mathrm{Cl}) \\
(\mathrm{N}=204,283)\end{array}$ \\
\hline \multicolumn{2}{|l|}{ Age } \\
\hline 18-25 (ref.) & 1.00 \\
\hline $26-34$ & $1.22(1.17-1.28)$ \\
\hline $35-49$ & $0.95(0.90-1.00)$ \\
\hline $50+$ & $0.65(0.62-0.69)$ \\
\hline \multicolumn{2}{|l|}{ Sex } \\
\hline Male & $1.60(1.53-1.66)$ \\
\hline Female (ref.) & 1.00 \\
\hline \multicolumn{2}{|l|}{ Race/ethnicity } \\
\hline Non-Hispanic White & $1.46(1.35-1.58)$ \\
\hline Non-Hispanic Black (ref.) & 1.00 \\
\hline Hispanic & $0.94(0.86-1.03)$ \\
\hline Asian/Native Hawaiian/Pacific Islander & $0.72(0.62-0.83)$ \\
\hline Other & $1.04(0.90-1.21)$ \\
\hline \multicolumn{2}{|l|}{ Annual household income } \\
\hline$\leq \$ 49,999$ (ref.) & 1.00 \\
\hline$\$ 50,000-\$ 74,999$ & $1.55(1.46-1.64)$ \\
\hline$\geq \$ 75,000$ & $1.80(1.72-1.88)$ \\
\hline \multicolumn{2}{|l|}{ Population density } \\
\hline Large metro & $1.06(1.00-1.12)$ \\
\hline Small metro & $1.10(1.04-1.17)$ \\
\hline Non metro (ref.) & 1.00 \\
\hline \multicolumn{2}{|l|}{ Alcohol abuse/dependence (past-year) } \\
\hline None (ref.) & 1.00 \\
\hline Abuse & $9.44(8.79-10.14$ \\
\hline Dependence & $5.99(5.54-6.47)$ \\
\hline Year & $0.97(0.96-0.98)$ \\
\hline \multicolumn{2}{|l|}{ Substance use type } \\
\hline Alcohol only (ref.) & 1.00 \\
\hline Prescription opioids only ${ }^{a}$ & $1.65(1.47-1.86)$ \\
\hline Marijuana only ${ }^{a}$ & $2.18(2.04-2.32)$ \\
\hline Other single drug ${ }^{a}$ & $2.12(1.88-2.39)$ \\
\hline Prescription opioids-marijuana ${ }^{a}$ & $2.71(2.43-3.02)$ \\
\hline Multiple prescription drugs ${ }^{a}$ & $2.83(2.35-3.41)$ \\
\hline Other multiple drugs ${ }^{\text {a }}$ & $3.68(3.40-3.97)$ \\
\hline
\end{tabular}

OR Odds Ratio, Cl Confidence Interval, Ref. reference group

${ }^{a}$ Past-year drug use, regardless of pas-year alcohol use status Boldface: $p<.01$

In recent years, there has been a significant change in laws surrounding prescription opioids and marijuana, such as prescription drug monitoring program (PDMP) and marijuana legalization [46, 47]. Thus, it is necessary to further assess the impacts of such laws on DUIA.
PDMP is a state-level database that tracks controlled substance prescriptions. Studies have reported some positive effects of PDMP on reducing prescription drug misuse [48-50]. Considering the high probability of use of both alcohol and prescription drugs [16, 17, 21, 51], it would be important to assess long-term impacts of PDMP on the DUIA occurrence as well as prescription drug misuse. State marijuana legalization laws also have changed over time in the United States. Available data have suggested that marijuana legalization appeared to contribute to the reduction in alcohol consumption [52, 53]. However, current evidence is insufficient to determine how marijuana legalization could influence alcohol impaired driving [54]. Given the lack of evidence, additional research is needed to understand the mechanism underlying the effects of policy intervention, such as PDMP and marijuana legalization, on DUIA among subtypes of prescription opioids and marijuana users.

This study also found that the strength of associations with DUIA varied by substance use type. Prescription opioids only users had 1.65 times higher odds of DUIA than alcohol only users. This may be due to a higher prevalence of alcohol abuse/dependence among prescription opioids only users than alcohol only users in this sample, and alcohol abuse/dependence was positively associated with DUIA in the adjusted analysis. A previous study also found that prescription opioid misuse was more prevalent among people with alcohol use disorder than people without alcohol use disorder [55]. Marijuana and other single drug users also had increased odds of DUIA than alcohol only users. Using two or more drugs was strongly associated with DUIA, which is consistent with previous research examining association of being arrest for driving under the influence [56]. Of different types of multiple drug use, the highest adjusted OR was associated with other multiple drug use (adjusted OR $=3.68$ ), followed by multiple prescription drugs (adjusted $\mathrm{OR}=2.83$ ) and prescription opioids-marijuana (adjusted $\mathrm{OR}=2.71$ ). When designing and implementing DUIA prevention programs, it is important to identify high-risk groups of DUIA, such as multiple drugs users with alcohol use disorder, so that they can receive intensive interventions. Several studies have documented the effectiveness of a social norm strategy in reducing impaired driving [57, 58]. Based on our study findings, social norms interventions should be implemented by addressing substance use pattern in order to improve their effectiveness. For example, multiple drug users could be exposed to the social norms interventions more frequently (e.g., increasing duration or number of sessions) than alcohol only or single drug users.

This study also revealed a number of variables associated with DUIA. Younger age, male sex, being White, higher income, and alcohol abuse/dependence were 
significant predictors of DUIA. Interestingly, higher-income people were more likely to report DUIA than lower-income people. A previous study found that higher-income people tended to have higher alcohol consumption [59], which may explain the positive association between higher-income and DUIA. In light of these findings, consistent monitoring and education programs should be provided, particularly for young white males. Alcohol abuse/dependence were the most powerful predictors of DUIA. Alcohol abuse/dependence were also more prevalent among drug use groups than alcohol use only group in this study sample, which might attributable to the elevated odds of DUIA among all other substance use groups, compared with alcohol only use group. Such findings underscore the importance of DUIA prevention programs targeting alcohol and other substance users, especially those with alcohol use disorder. As part of DUIA preventive efforts, screening and treatment for alcohol and drug use disorders should be implemented in clinical settings [60, 61]. Alcohol consumption monitoring also appeared to be effective in preventing impaired driving [62]. Consistent monitoring of alcohol consumption and drug use, particularly for people with a substance use disorder, would play a vital role in preventing DUIA.

This study has some limitations. First, this study could not establish temporal or causal relationship due to the nature of the cross-sectional data. Future longitudinal studies are needed to explore the extent to which different types of substance use lead to DUIA. In addition, the prevalence of DUIA was estimated based on self-reports, which might lead to biased prevalence estimations. It is possible that respondents did not report correctly due to social stigma associated with DUIA. Additional research investigating the prevalence of DUIA from oral fluid and/or blood samples may provide a more accurate estimate. Lastly, this study focused on self-reported use of one or more drugs in the past year. The precise timing of use could not be determined from the data source. Previous studies showed that simultaneous use of multiple drugs was more strongly associated with alcohol-related problems as well as unsafe driving than concurrent use of multiple drugs $[16,63]$. Thus, examining differences in DUIA risk between simultaneous and concurrent users of multiple drugs would be of interest for further research.

\section{Conclusions}

This study demonstrated different time trends of DUIA by substance use type. From 2008 to 2014, DUIA prevalence decreased significantly in all substance use groups, except for other single drug users, with the largest reduction noted among multiple prescription drug users. Although the estimate was not statistically significant, single drug users also showed a decreasing trend of DUIA. Our results lend support in implementing DUIA prevention interventions that should be tailored to substance use type to more effectively reduce DUIA. Furthermore, the strength of associations with DUIA varied by substance use type. In particular, using two or more drugs yielded the highest odds of DUIA, indicating a need for more intensive DUIA intervention programs targeting multiple drug users. Younger people, male, white (vs. black), those with higher income (vs. those with household incomes of less than \$49,999), and people with alcohol use disorder were also more likely to report DUIA. Our findings highlight the importance of enhanced DUIA interventions by adding individual sessions that focus on high-risk subgroups [64], such as multiple drug users and individuals with the above characteristics. Additionally, policy makers should take into account the variations in the likelihood of DUIA by substance use type when designing and implementing strategies for reducing DUIA. Further research is warranted to clarify whether simultaneous use of multiple drugs leads to higher risk of DUIA than concurrent use of multiple drugs.

\section{Abbreviations \\ AAPC: Average annual percent change; APC: Annual percent change; Cl: Confidence interval; DUIA: Driving under the influence of alcohol; MTF: Monitoring the Future; NSDUH: National Survey on Drug Use and Health; OR: Odds ratio; PDMP: Prescription drug monitoring program}

\section{Acknowledgements}

Not applicable.

\section{Funding}

This work was made possible by research support from the U.S. National Institutes of Health.

(UG1DA040317 and R01MD007658, Principal Investigator, Li-Tzy Wu). The sponsoring agency had no further role in the study design and analysis, the writing of the report, or the decision to submit the paper for publication. The opinions expressed in this paper are solely those of the authors.

\section{Availability of data and materials}

The datasets used and/or analyzed during the current study are available from the corresponding author on reasonable request.

\section{Authors' contributions}

JYP contributed to the design and concept for this manuscript, conducted statistical analysis, and drafted the manuscripts. LTW contributed to the design and concept for this manuscript, drafted the manuscripts, and supervised the work. All authors have read and approved the final manuscript before submission

Ethics approval and consent to participate

The datasets from the National Survey on Drug Use and Health are deidentified and public available, which cannot be individually identifiable and therefore not involve human subjects.

\section{Consent for publication}

Not applicable.

\section{Competing interests}

LTW also has received research funding from Patient-Centered Outcomes Research Institute, Duke Endowment, Centers for Disease Control and Prevention, and Alkermes Inc. JYP has no conflict of interest to report. 


\section{Publisher's Note}

Springer Nature remains neutral with regard to jurisdictional claims in published maps and institutional affiliations.

\begin{abstract}
Author details
'Department of Psychiatry and Behavioral Sciences, BOX 3903, Duke University School of Medicine, Durham, NC, USA. ${ }^{2}$ Department of Medicine, Division of General Internal Medicine, Duke University School of Medicine, Durham, NC, USA. ${ }^{3}$ Duke Clinical Research Institute, Duke University School of Medicine, Durham, NC, USA. ${ }^{4}$ Center for Child and Family Policy, Sanford School of Public Policy, Duke University, Durham, NC, USA.
\end{abstract}

Received: 17 May 2018 Accepted: 24 April 2019

Published online: 04 May 2019

\section{References}

1. Centers for Disease Control and Prevention. Vital signs: alcohol-impaired driving among adults_-United States, 2010. MMWR Morb Mortal Wkly Rep. 2011;60(39):1351-6.

2. Lipari RN, Hughes A, Bose J. Driving under the influence of alcohol and illicit drugs. The CBHSQ report: Rockville. In: MD: Substance Abuse and Mental Health Services Administration; 2016.

3. Hingson R, Zha W, Smyth D. Magnitude and trends in heavy episodic drinking, alcohol-impaired driving, and alcohol-related mortality and overdose hospitalizations among emerging adults of college ages 18-24 in the United States, 1998-2014. J Stud Alcohol Drugs. 2017;78(4):540-8.

4. Berning A, Compton R, Wochinger K. Results of the 2013-2014 National Roadside Survey of alcohol and drug use by drivers. (traffic safety facts research note. Report no. DOT HS 812 118). Washington, DC: National Highway Traffic Safety Administration; 2015.

5. Center for Behavioral Health Statistics and Quality. Results from the 2016 National Survey on Drug Use and Health: Detailed tables. Rockville: Substance Abuse and Mental Health Services Administration; 2017. https:// www.samhsa.gov/data/sites/default/files/NSDUH-DetTabs-2016/NSDUHDetTabs-2016.pdf. Accessed 27 Dec 2017.

6. Ahlm K, Björnstig U, Oström M. Alcohol and drugs in fatally and non-fatally injured motor vehicle drivers in northern Sweden. Accid Anal Prev. 2009; 41(1):129-36.

7. Mørland J, Steentoft A, Simonsen KW, Ojanperä I, Vuori E, et al. Drugs related to motor vehicle crashes in northern European countries: a study of fatally injured drivers. Accid Anal Prev. 2011;43(6):1920-6.

8. Taylor B, Rehm J. The relationship between alcohol consumption and fatal motor vehicle injury: high risk at low alcohol levels. Alcohol Clin Exp Res. 2012;36(10):1827-34

9. National Center for. Statistics and analysis. 2016 fatal motor vehicle crashes: overview. (traffic safety facts research note. Report no. DOT HS 812 456). Washington, DC: National Highway Traffic Safety Administration; 2017.

10. Brady JE, Li G. Trends in alcohol and other drugs detected in fatally injured drivers in the United States, 1999-2010. Am J Epidemiol. 2014;179(6):692-9.

11. Blincoe LJ, Miller TR, Zaloshnja E, Lawrence BA. The economic and societal impact of motor vehicle crashes, 2010. (revised) (report no. DOT HS 812 013). Washington, DC: National Highway Traffic Safety Administration; 2015.

12. Flowers NT, Naimi TS, Brewer RD, Elder RW, Shults RA, et al. Patterns of alcohol consumption and alcohol-impaired driving in the United States. Alcohol Clin Exp Res. 2008;32(4):639-44.

13. Jewett A, Shults RA, Banerjee T, Bergen G. Alcohol-impaired driving among adults-United States, 2012. MMWR: Morbidity Mortal Wkly Rep. 2015;64(30): 814-7.

14. Quinlan KP, Brewer RD, Siegel P, Sleet DA, Mokdad AH, et al. Alcoholimpaired driving among U.S. adults, 1993-2002. Am J Prev Med. 2005;28(4): 346-50.

15. Schwartz J, Beltz L. Trends in female and male drunken driving prevalence over thirty years: triangulating diverse sources of evidence (1985-2015). Addict Behav. 2018;84:7-12.

16. McCabe SE, Cranford JA, Morales M, Young A. Simultaneous and concurrent polydrug use of alcohol and prescription drugs: prevalence, correlates, and consequences. J Stud Alcohol. 2006;67(4):529-37.

17. McCabe SE, Veliz P, Patrick ME. High-intensity drinking and nonmedical use of prescription drugs: results from a national survey of 12th grade students. Drug Alcohol Depend. 2017;178:372-9.
18. Midanik LT, Tam TW, Weisner C. Concurrent and simultaneous drug and alcohol use: results of the 2000 National Alcohol Survey. Drug Alcohol Depend. 2007;90(1):72-80.

19. Subbaraman MS, Kerr WC. Simultaneous versus concurrent use of alcohol and cannabis in the National Alcohol Survey. Alcohol Clin Exp Res. 2015; 39(5):872-9.

20. Terry-McElrath YM, O'Malley PM, Johnston LD. Simultaneous alcohol and marijuana use among U.S. high school seniors from 1976 to 2011: trends, reasons, and situations. Drug Alcohol Depend. 2013;133(1):71-9.

21. McCabe SE, West BT, Teter CJ, Boyd CJ. Co-ingestion of prescription opioids and other drugs among high school seniors: results from a national study. Drug Alcohol Depend. 2012;126(1-2):65-70.

22. Ch'ng CW, Fitzgerald M, Gerostamoulos Cameron P, Bui D, Drummer $\mathrm{OH}$, et al. Drug use in motor vehicle drivers presenting to an Australian, adult major trauma Centre. Emerg Med Australas. 2007:19(4):359-65.

23. Dubois S, Mullen N, Weaver B, Bédard M. The combined effects of alcohol and cannabis on driving: impact on crash risk. Forensic Sci Int. 2015;248:94-100.

24. Rudisill TM, Zhao S, Abate MA, Coben JH, Zhu M. Trends in drug use among drivers killed in U.S. traffic crashes, 1999-2010. Accid Anal Prev. 2014; 70:178-87.

25. Smith GW, Farrell M, Bunting BP, Houston JE, Shevlin M. Patterns of polydrug use in Great Britain: findings from a national household population survey. Drug Alcohol Depend. 2011;113(2-3):222-8.

26. Teeters JB, Pickover AM, Dennhardt AA, Martens MP, Murphy JG. Elevated alcohol demand is associated with driving after drinking among college student binge drinkers. Alcohol Clin Exp Res. 2014;38(7):2066-72.

27. Bogstrand ST, Gjerde H, Normann PT, Rossow I, Ekeberg $\varnothing$. Alcohol, psychoactive substances and non-fatal road traffic accidents--a case-control study. BMC Public Health. 2012;12:734.

28. Gjerde H, Normann PT, Christophersen AS, Samuelsen SO, Mørland J. Alcohol, psychoactive drugs and fatal road traffic accidents in Norway: a case-control study. Accid Anal Prev. 2011:43(3):1197-203.

29. Li G, Brady JE, Chen Q. Drug use and fatal motor vehicle crashes: a casecontrol study. Accid Anal Prev. 2013:60:205-10.

30. Fiellin LE, Tetrault JM, Becker WC, Fiellin DA, Hoff RA. Previous use of alcohol, cigarettes, and marijuana and subsequent abuse of prescription opioids in young adults. J Adolesc Health. 2013;52(2):158-63.

31. Olfson M, Wall MM, Liu SM, Blanco C. Cannabis use and risk of prescription opioid use disorder in the United States. Am J Psychiatry. 2018;175(1):47-53.

32. Wu LT, Woody GE, Yang C, Blazer DG. Subtypes of nonmedical opioid users: results from the national epidemiologic survey on alcohol and related conditions. Drug Alcohol Depend. 2010;112(1-2):69-80.

33. Drummer OH, Gerostamoulos J, Batziris H, Chu M, Caplehorn JR, et al. The incidence of drugs in drivers killed in Australian road traffic crashes. Forensic Sci Int. 2003;134(2-3):154-62

34. Bezemer KD, Smink BE, van Maanen R, Verschraagen M, de Gier JJ. Prevalence of medicinal drugs in suspected impaired drivers and a comparison with the use in the general Dutch population. Forensic Sci Int. 2014:241:203-11.

35. Dischinger P, Li J, Smith GS, Ho S, Auman K, et al. Prescription medication usage and crash culpability in a population of injured drivers. Ann Adv Automot Med. 2011;55:207-16.

36. Center for Behavioral Health Statistics and Quality. Behavioral health trends in the United States: Results from the 2014 National Survey on Drug Use and Health, HHS Publication No. SMA 15-4927, NSDUH Series H-50, Rockville, MD: Substance Abuse and Mental Health Services Administration; 2015. https://www.samhsa.gov/data/sites/default/files/NSDUH-FRR1-2014/ NSDUH-FRR1-2014.pdf. Accessed 26 May 2017.

37. Caetano R, McGrath C. Driving under the influence (DUI) among U.S. ethnic groups. Accid Anal Prev. 2005;37(2):217-24.

38. Hingson RW, Heeren T, Edwards EM. Age at drinking onset, alcohol dependence, and their relation to drug use and dependence, driving under the influence of drugs, and motor-vehicle crash involvement because of drugs. J Stud Alcohol Drugs. 2008;69(2):192-201.

39. American Psychiatric Association. Diagnostic and statistical manual of mental disorders. 4th ed text rev. Washington, DC: American Psychiatric Association; 2000.

40. Chou SP, Dawson DA, Stinson FS, Huang B, Pickering RP, et al. The prevalence of drinking and driving in the United States, 2001-2002: results from the national epidemiological survey on alcohol and related conditions. Drug Alcohol Depend. 2006;83(2):137-46. 
41. Naimi TS, Nelson DE, Brewer RD. Driving after binge drinking. Am J Prev Med. 2009;37(4):314-20.

42. Shults RA, Kresnow MJ, Lee KC. Driver- and passenger-based estimates of alcohol-impaired driving in the U.S., 2001-2003. Am J Prev Med. 2009;36(6): 515-22.

43. Font-Ribera L, Garcia-Continente X, Pérez A, Torres R, Sala N, et al. Driving under the influence of alcohol or drugs among adolescents: the role of urban and rural environments. Accid Anal Prev. 2013;60:1-4.

44. Barrio G, Pulido J, Bravo MJ, Lardelli-Claret P, Jiménez-Mejías E, de la Fuente $L$. An example of the usefulness of joinpoint trend analysis for assessing changes in traffic safety policies. Accid Anal Prev. 2015;75:292-7.

45. Ries LA, Wingo PA, Miller DS, Howe HL, Weir HK, et al. The annual report to the nation on the status of cancer, 1973-1997, with a special section on colorectal cancer. Cancer. 2000;88:2398-424.

46. Haffajee RL, Jena AB, Weiner SG. Mandatory use of prescription drug monitoring programs. JAMA. 2015;313(9):891-2.

47. Subbaraman MS, Kerr WC. Support for marijuana legalization in the US state of Washington has continued to increase through 2016. Drug Alcohol Depend. 2017;175:205-9.

48. Patrick SW, Fry CE, Jones TF, Buntin MB. Implementation of prescription drug monitoring programs associated with reductions in opioid-related death rates. Health Aff (Millwood). 2016;35(7):1324-32.

49. Pardo B. Do more robust prescription drug monitoring programs reduce prescription opioid overdose? Addiction. 2017;112(10):1773-83.

50. Reifler LM, Droz D, Bailey JE, Schnoll SH, Fant R, et al. Do prescription monitoring programs impact state trends in opioid abuse/misuse? Pain Med. 2012;13(3):434-42.

51. Garnier LM, Arria AM, Caldeira KM, Vincent KB, O'Grady KE, et al. Nonmedical prescription analgesic use and concurrent alcohol consumption among college students. Am J Drug Alcohol Abuse. 2009;35(5):334-8.

52. Anderson MD, Hansen B, Rees DI. Marijuana laws, traffic fatalities, and alcohol consumption. J Law Econ. 2013;56:333-63.

53. Anderson DM, Rees DI. The legalization of recreational marijuana: how likely is the worst-case scenario? J Policy Anal Manage. 2014 Winter;33(1):221-32.

54. Salomonsen-Sautel S, Min SJ, Sakai JT, Thurstone C, Hopfer C. Trends in fatal motor vehicle crashes before and after marijuana commercialization in Colorado. Drug Alcohol Depend. 2014:140:137-44.

55. McCabe SE, Cranford JA, Boyd CJ. The relationship between past-year drinking behaviors and nonmedical use of prescription drugs: prevalence of co-occurrence in a national sample. Drug Alcohol Depend. 2006;84(3):281-8.

56. Bogstrand ST, Gjerde $H$. Which drugs are associated with highest risk for being arrested for driving under the influence? A case-control study. Forensic Sci Int. 2014;240:21-8.

57. Linkenbach J, Perkins HW. Montana's MOST of us Don't drink and drive campaign: a social norms strategy to reduce impaired driving among 21-34 year olds. National highway traffic safety administration. Washington, DC; 2005. Final Report

58. Perkins HW, Linkenbach JW, Lewis MA, Neighbors C. Effectiveness of social norms media marketing in reducing drinking and driving: a statewide campaign. Addict Behav. 2010:35(10):866-74.

59. Moore AA, Gould R, Reuben DB, Greendale GA, Carter MK, et al. Longitudinal patterns and predictors of alcohol consumption in the United States. Am J Public Health. 2005;95(3):458-65.

60. Osilla KC, Kulesza M, Miranda J. Bringing alcohol treatment to driving under the influence programs: perceptions from first-time offenders. Alcohol Treat Q. 2017;35(2):113-29.

61. Schermer CR, Moyers TB, Miller WR, Bloomfield LA. Trauma center brief interventions for alcohol disorders decrease subsequent driving under the influence arrests. J Trauma. 2006;60(1):29-34

62. Voas RB, DuPont RL, Talpins SK, Shea CL. Towards a national model for managing impaired driving offenders. Addiction. 2011:106(7):1221-7.

63. Terry-McElrath YM, O'Malley PM, Johnston LD. Alcohol and marijuana use patterns associated with unsafe driving among U.S. high school seniors: high use frequency, concurrent use, and simultaneous use. J Stud Alcohol Drugs. 2014;75(3):378-89.

64. Wells-Parker E, Williams M. Enhancing the effectiveness of traditional interventions with drinking drivers by adding brief individual intervention components. J Stud Alcohol. 2002;63(6):655-64.

\section{Ready to submit your research? Choose BMC and benefit from:}

- fast, convenient online submission

- thorough peer review by experienced researchers in your field

- rapid publication on acceptance

- support for research data, including large and complex data types

- gold Open Access which fosters wider collaboration and increased citations

- maximum visibility for your research: over $100 \mathrm{M}$ website views per year

At BMC, research is always in progress.

Learn more biomedcentral.com/submissions 